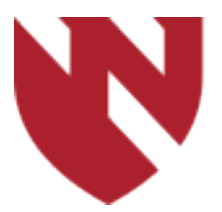

October 2021

\title{
A Unique Mode of Failure in the Non-Contact Bridging Periprosthetic Plating System
}

\author{
Erin L. Stockwell \\ University of Nebraska Medical Center \\ Matthew Mormino \\ University of Nebraska Medical Center \\ Justin C. Siebler \\ University of Nebraska Medical Center
}

Tell us how you used this information in this short survey.

Follow this and additional works at: https://digitalcommons.unmc.edu/gmerj

Part of the Higher Education Commons, and the Medicine and Health Sciences Commons

\section{Recommended Citation}

Stockwell, E. L., Mormino, M., , Siebler, J. C. A Unique Mode of Failure in the Non-Contact Bridging Periprosthetic Plating System. Graduate Medical Education Research Journal. 2021 Oct 04; 3(1). https://digitalcommons.unmc.edu/gmerj/vol3/iss1/26 


\section{A Unique Mode of Failure in the Non-Contact Bridging Periprosthetic Plating System}

\section{Creative Commons License}

\section{(c) (1) $\Theta$}

This work is licensed under a Creative Commons Attribution-Noncommercial-No Derivative Works 4.0 License. 


\section{A Unique Mode of Failure in the Non-Contact Bridging Periprosthetic Plating System}

\section{Erin L. Stockwell ${ }^{1}$, Matthew A. Mormino ${ }^{1}$, Justin C. Siebler ${ }^{1}$}

${ }^{1}$ University of Nebraska Medical Center, College of Medicine, Department of Orthopaedic Surgery

Mentors: Matthew Mormino, Justin Siebler

Program: Orthopaedic Surgery Residency Program

Type: Case Report

Background: Although lateral locking plates are often a preferred and successful fixation construct for the treatment of periprosthetic proximal and distal femur fractures, certain complications and modes of failure have been well-described with their use. We experienced two cases of a unique mode of failure in the Non-Contact Bridge Periprosthetic Plating System (Zimmer Biomet) in which a nonlocked screw fretted through the annular seating of the plate. Appropriate patient consent was obtained for the use of these cases for educational purposes.

Case 1: An 85-year-old woman with a history of dementia and osteoporosis sustained a right proximal femur periprosthetic fracture after suffering a ground level fall. Open reduction and internal fixation were performed and there were no identified complications on radiographs obtained 7 weeks postoperatively. Radiographs obtained 11 weeks post-operatively demonstrated fretting of the distal-most screw through the plate (Fig. 1a).

Case 2: A 73-year-old man with a history of multiple myeloma, diabetes, and chronic left lower extremity weakness sustained a right periprosthetic supracondylar distal femur fracture after suffering a ground level fall. Open reduction and internal fixation was performed and there were no identified complications on radiographs obtained 8 weeks post-operatively. Radiographs obtained 14 weeks post-operatively demonstrated fretting of the distal-most screw placed

Conclusion: Periprosthetic fractures are complex orthopaedic injuries. Lateral locking plates are often the preferred treatment because of their excellent stability and ability proximal to the fracture site (Fig. 1b).

to be placed in a minimally invasive manner. Plate or screw fracture and screw pull-out are well-documented complications, however no literature exists demonstrating the unique mode of failure exhibited in our clinical cases.

https://doi.org/10.32873/unmc.dc.gmerj.3.1.046
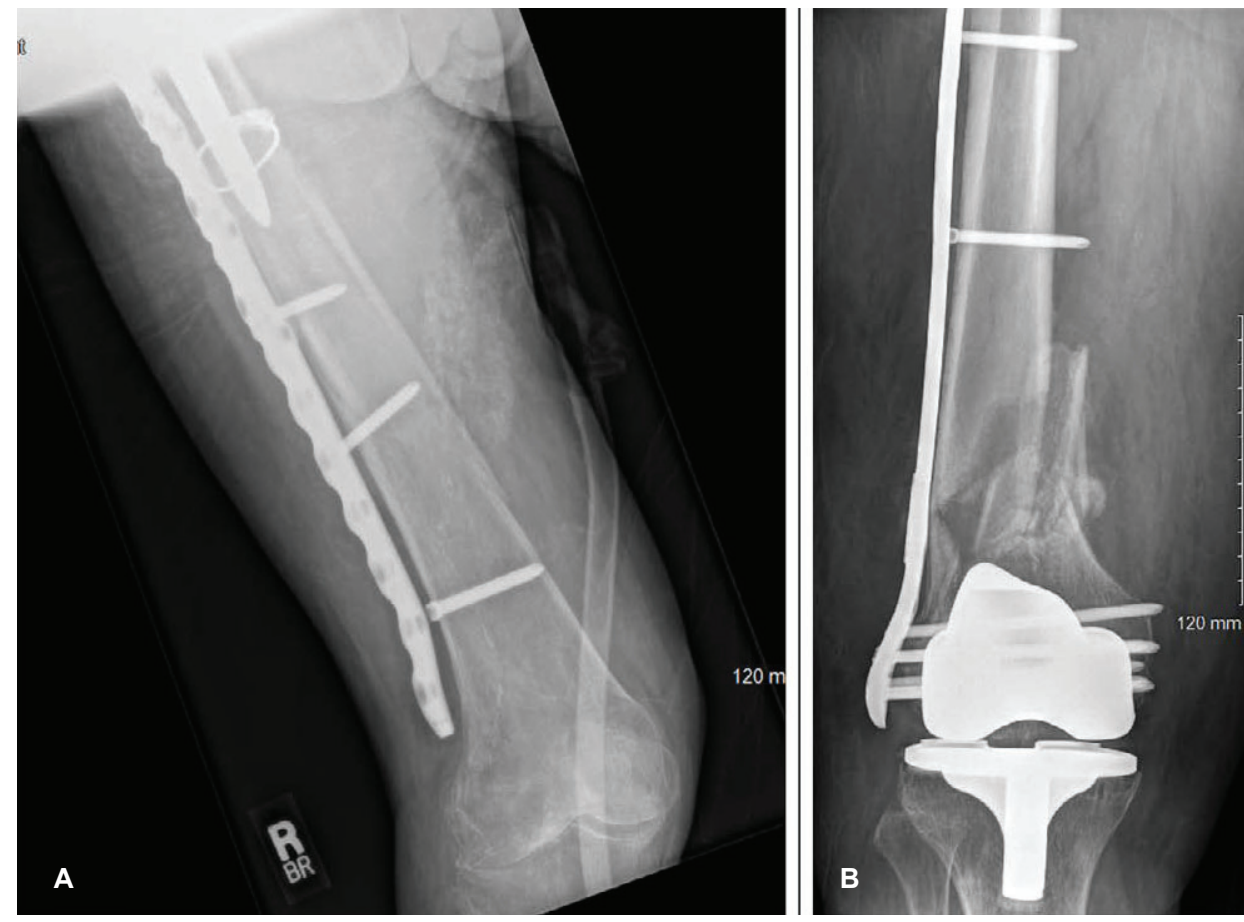

Figure 1. (A) Case 1. AP radiograph of the right femur obtained 11 weeks post-operatively demonstrates fretting of the distal most screw through the annular seating of the plate. (B) Case 2. AP radiograph of the right femur obtained 14 weeks post-operatively demonstrates fretting of the distalmost screw placed proximal to the fracture site.

\section{Proceedings of the 3rd Annual Graduate Medical Education Research Symposium | Poster Presentations — Original Research}

\section{Notification of High-Risk Opiate Prescriptions Reduces Dangerous Practices}

A. Beck', W. Zeger ${ }^{1}$, C. Johnson², K. Baack ${ }^{1}$, H. Nichols ${ }^{1}$

${ }^{1}$ University of Nebraska Medical Center, College of Medicine, Department of Emergency Medicine ${ }^{2}$ Nebraska Medicine

Mentor: Wesley Zeger

Program: Emergency Medicine Residency Program

Type: Original Research

Background: The U.S. is still experiencing an opioid epidemic. Current guidelines from the Centers for Disease Control (CDC) recommend no more than 50 Morphine
Milligram Equivalent (MME) per day for initial prescriptions, but familiarity with conversion may be preventing providers from following these guidelines. A standard (MME) calculator was implemented in our Electronic Health Record. We sought to determine whether inclusion of this calculator and an associated warning for prescriptions above $50 \mathrm{MME}$ were effective in reducing high-risk opiate prescriptions.
Methods: An IRB approved this study. A retrospective chart review was performed, and all opiate prescriptions from the emergency department for three months preceding and three months following the calculator was included. Discharge prescriptions were then converted to MME per day utilizing the CDC's conversion table. Statistical calculations were performed with a twosample T-test with unequal variance and ChiSquare statistic in Excel. 